\title{
Contribution of the Compressed Air Energy Storage in the Reduction of GHG - Case Study: Application on the Remote Area Power Supply System
}

Hussein Ibrahim and Adrian llinca

Additional information is available at the end of the chapter

http://dx.doi.org/10.5772/50131

\section{Introduction}

There are many different interpretations and classifications in use today to describe rural and/or remote areas for the purposes of discussing methods of electrification. Some useful examples are as follows [1]:

1. By density and concentration or clustering - setting the context of the environment or geography:

- Small communities, villages or even towns that are remote from other habitation,

- Dispersed households, farms and enterprises of low density over wide areas or regions,

- Community clusters or villages surrounded by lower density dispersed households,

- Geographically on the same land mass, but separated by physical obstacles such as long distances, mountainous terrain, or possibly separated by water such as island communities,

2. By energy use:

- By power and energy (or load factor=f(energy/power)) and load profile,

- By application: household, commercial enterprise, institution, agricultural processing, etc.

3. By choice and method of energy provision:

- Reticulated electricity, connected to some form of larger grid, or a local micro grid,

- Reticulated/piped fuel such as natural gas, LPG, fuel oil, diesel, 
- Transported fuel such as natural gas, LPG, fuel oil, diesel, by land or sea transport,

- Reliance on renewable energy products such as hydro, solar photovoltaic (PV), wind, waves, tides,

The most suitable method of electricity provision (technology, business model, etc.) will usually depend on the combination of the geographic context, the consumer need, and the possibilities that are available and affordable to provide the energy requirements. Therefore, the most appropriate solutions in one place might be quite unsuitable in another [1].

Clusters and communities that are very remote from other habitation will generally be supplied by some form of centralised local generation, or via a connection to a larger but somewhat remote grid.

\section{Challenges related to the electrification of remote areas}

Today, diesel generators are mainly used, around the world, as emergency supply sets in telecommunication, public buildings, hospitals, or other technical installations (meteorological systems, tourist facilities, farms, etc.), and as standalone military and marine power plants, as well as the reliable isolated power source for islands or remote villages placed far from the power network [2]. In fact, there are two general methods of supplying electricity to remote areas: grid extension and the use of diesel generators. Grid extension can be very expensive in many locations. Diesel generators are therefore the only viable option for remote area electrification [3].

Classic gensets based on internal combustion engines are equipped with synchronous generators, therefore fixed speed operation is required. It gives low efficiency during low load operation (figure 1). It is not critical in emergency case operated sets, but very important in continuously operated systems, where fuel consumption is significant economic and logistic aspect. In fact, remote areas with relatively small communities generally show significant variation between the time of peak loads and the time of minimum loads. A typical example of a load profile of a remote community in Western Australia is shown below in figure 2. Diesel-powered electric generators are typically sized to meet the peak demand during the evening but must run at very low loads during "offpeak" hours during the day and night. This low-load operation results in poor fuel efficiency and increased operation and maintenance costs [3].

Moreover, low load operation of diesel genset at synchronous speed reduces the engine lifetime, by incomplete combustion of the fuel, therefore an additional dump load is required to improve the combustion process. The efficiency and fuel combustion at low load conditions can be improved by use of load adaptive adjustable speed operation of the genset [4]. In some remote locations, a dual diesel generator system is employed. When the load is light, the smaller generator is used; as the load increased, the manual switch is transferred to the larger generator. This approach results in some fuel savings, however managing this dual system is time consuming and impractical [3]. 


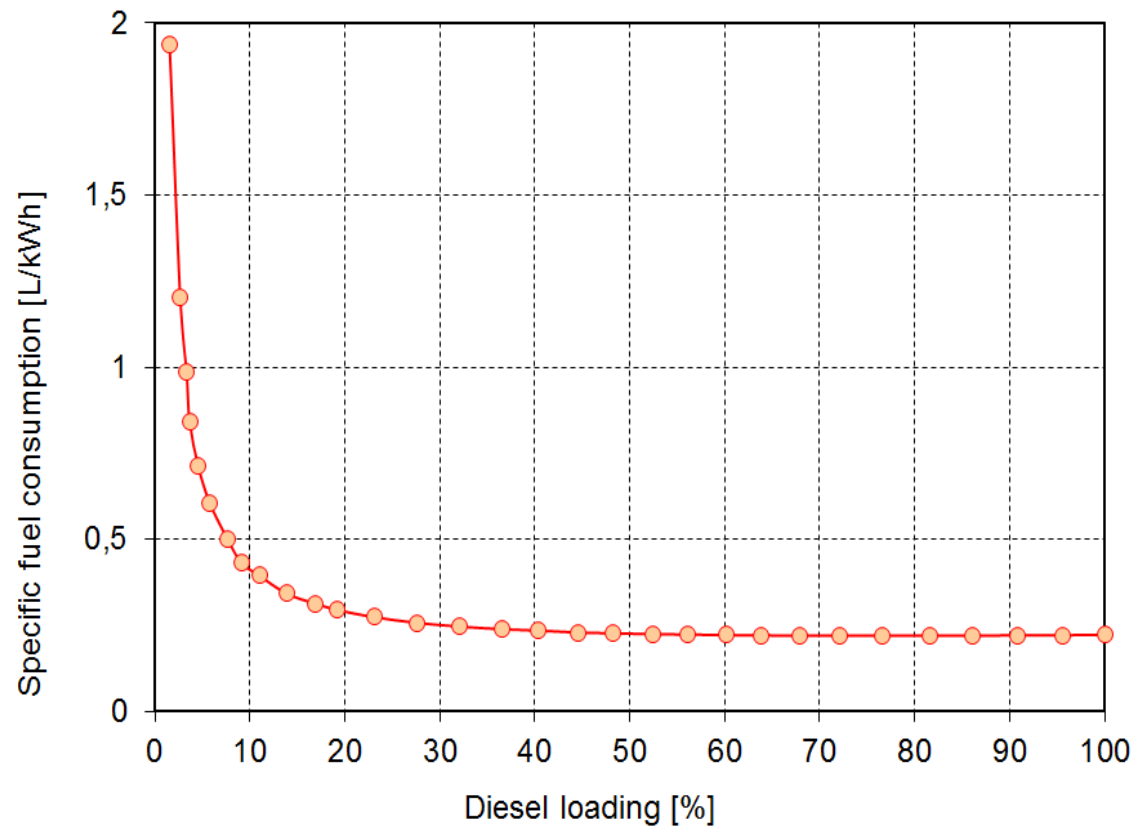

Figure 1. Example of a variation of diesel fuel consumption with loading

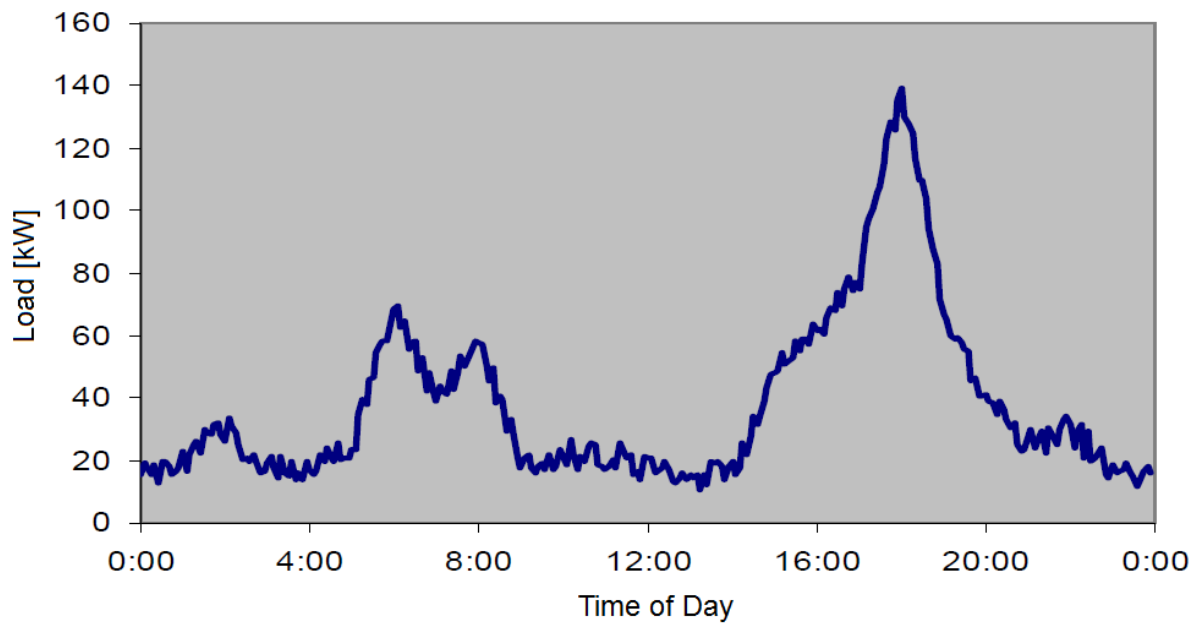

Figure 2. Typical load profile of a remote community [3] 


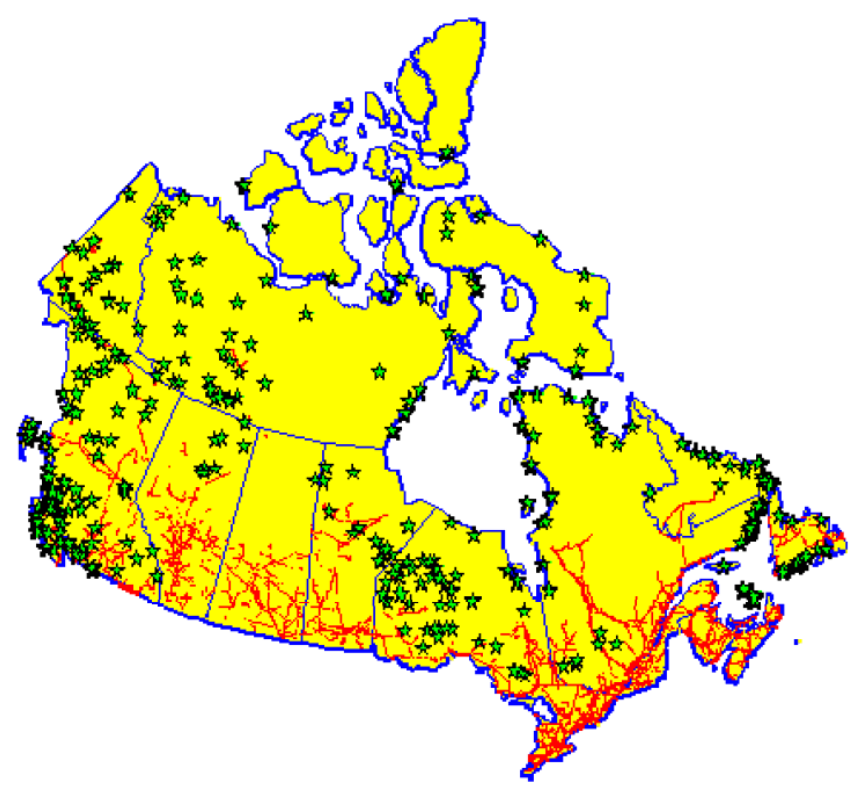

Figure 3. Canadian remote communities [5]

In Canada, approximately 200,000 people live in more than 300 remote communities (Yukon, TNO, Nunavut, islands) (figure 3) and are using diesel-generated electricity, responsible for the emission of 1.2 million tons of greenhouse gases (GHG) annually [6]. In Quebec province, there are over 14,000 subscribers distributed in about forty communities not connected to the main grid. Each community constitutes an autonomous network that uses diesel generators.

In Quebec, the total production of diesel power generating units is approximately $300 \mathrm{GWh}$ per year. In the meantime, the exploitation of the diesel generators is extremely expensive due to the oil price increase and transportation costs. Indeed, the communities are dependent on imported fossil fuels for most of their energy requirements. Also, there are exposed to diesel fuel price volatility, frequent fuel spills and high operation and maintenance costs including fuel transportation and bulk storage. Having said this however, in the past decade, diesel prices have more than doubled. High fuel costs have translated into tremendous increases in the cost of energy generation [3]. In Quebec for example, as the fuel should be delivered to remote locations, some of them reachable only during summer periods by barge, the cost of electricity produced by diesel generators reached in 2007 more than $50 \mathrm{cent} / \mathrm{kWh}$ in some communities, while the price for selling the electricity is established, as in the rest of Quebec, at approximately 6 cent/kWh [7]. The deficit is spread among all Quebec population as the total consumption of the autonomous grids is far from being negligible. In 2004, the autonomous networks represented 144MW of installed power, and the consumption was established at $300 \mathrm{GWh}$. Hydro-Quebec, the provincial utility, estimated at approximately 133 million CAD\$ the annual loss, resulting from the difference between the diesel electricity production cost and the uniform selling price of electricity [7]. 
Moreover, the electricity production by the diesel is ineffective, presents significant environmental risks (spilling), contaminates the local air and largely contributes to GHG emission. In all, we estimate at 140,000 tons annual GHG emission resulting from the use of diesel generators for the subscribers of the autonomous networks in Quebec. This is equivalent to GHG emitted by 35,000 cars during one year.

The use of diesel engines to supply power to rural communities has provided light and energy services to places where previously there has only been darkness. However, the rising cost of diesel fuel (brought on by higher oil prices and the environmental regulation for its transportation, use, and storage) combined with carbon emissions concerns is driving remote communities to look at alternative methods to supplement this power source. During the past few years, wind energy is increasingly used to reduce diesel fuel consumption, providing economic, environmental, social, and security benefits [8].

Wind-diesel systems have been the most successfully and widely hybrid power systems applied up to date. These systems are designed to use as much as possible wind power in order to lower diesel consumption. The challenge is to keep the power quality and stability of the system besides the variability of the wind power generation and diesel operational constraints [9]. Indeed, one of the disadvantages is the intermittent nature of wind power generation. Diesel engine driven synchronous generators operating in parallel with wind turbine must maintain a good voltage and frequency regulation against active and reactive load variations and wind speed changes [10]. Integration of a storage element with diesel and wind turbine is necessary in order to get a smooth power output from a wind turbine and to optimize energy use to further reduce consumption of diesel fuel [11]. The next sections present an overview of technical challenges of wind-diesel hybrid system (WDHS), the justification of the choice of compressed air as device of energy storage to be used with WDHS and the impact of using of this storage energy system on the fuel consumption of diesel generators and on the GHG emissions.

\section{Overview of wind-diesel hybrid system}

\subsection{Description of wind-diesel hybrid system}

A wind-diesel hybrid system is any autonomous electricity generating system using wind turbine(s) with diesel generator(s) to obtain a maximum contribution by the intermittent wind resource to the total power produced, while providing continuous high quality electric power [12]. Overview of typical wind-diesel installations can be found in [13]. In the most cases, the power of installed diesel gensets is much higher than the power of wind turbines. In peak, the wind turbines can cover even more than $90 \%$ of demanded power, but in long term the fuel saving is $10-15 \%$. The same level of fuel saving can be obtained by gensets based on power electronics, load adaptive, adjustable speed diesel without use of wind turbines. It is used in light mobile power gensets [14].

Figure 4 presents a schematic diagram of a generalized wind diesel system. As shown, this system consists of the following major components: 
- $\quad$ One or more wind turbines

- One or more diesel generator sets

- A consumer load

- An additional controllable or dump load

- A storage system

- A control unit (including possible load management)

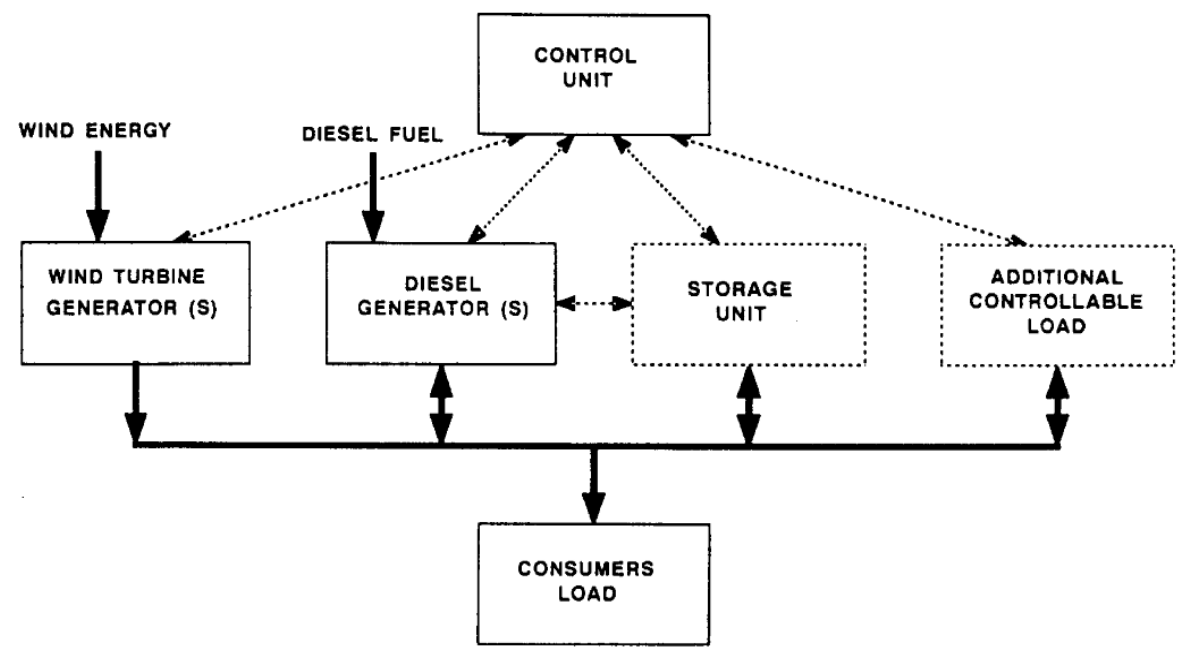

Figure 4. Schematic of generalized wind-diesel system [15]

\subsection{Classification of wind-diesel systems versus wind penetration rate}

Wind-Diesel hybrid power systems are particularly suited for locations where wind resource availability is high and the cost of diesel fuel and generator operation control the cost of electrical energy supplied. As a result of turbine developments the economics of wind power have now become competitive with conventional power source. The economy of operation of wind turbines is critically dependent on the wind speeds at the site. If the wind turbine is used along (high penetration of wind energy) with a diesel engine, the cost of power generation could be reduced, in addition to reducing greenhouse gas emission problems.

Penetration here is defined as the ratio of rated capacity of the wind energy source to the total system-rated capacity. It should also be noted that load patterns may also significantly affect system operation [15].

A classification system is used when discussing the amount of wind that is being integrated into the grid system (Table 1). A system is considered to be a high penetration system (figure 5) when the amount of wind produced at any time versus the total amount of energy produced is over $100 \%$. Low penetration systems (figure 6) are those with less than $50 \%$ peak instantaneous penetration and medium penetration systems have between $50 \%-100 \%$ 
of their energy being produced from wind at any one time. Low and medium penetration systems are a mature technology. High penetration systems, however, still have many problems, especially when installed with that capacity to operate in a diesel-off mode.

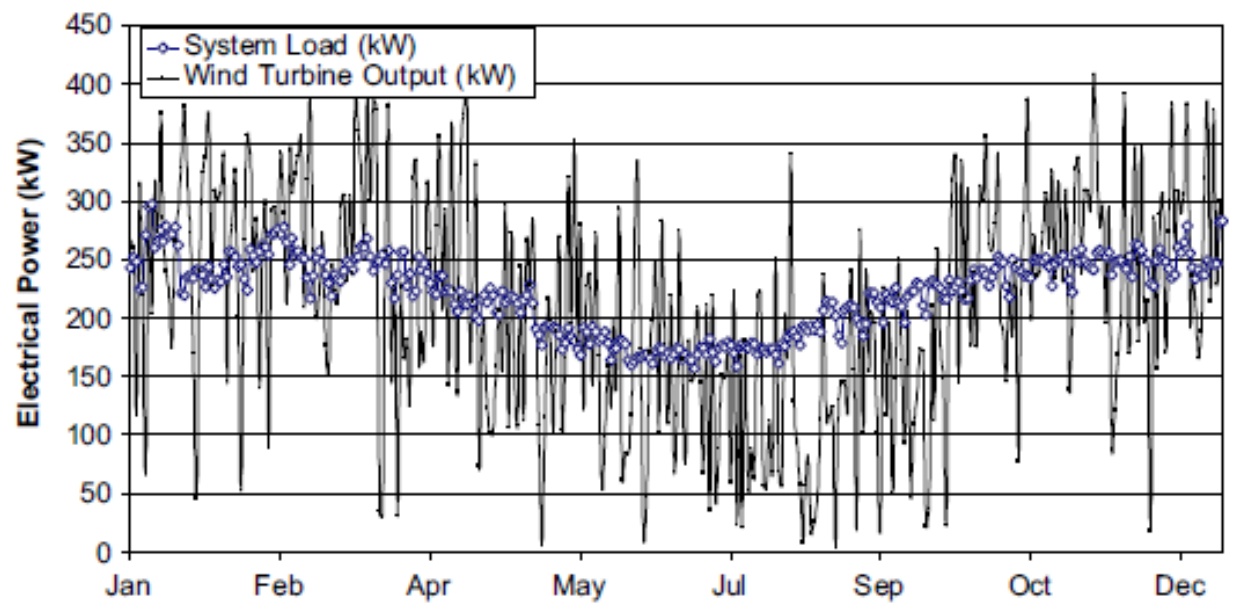

Figure 5. Example of a high-penetration wind-diesel system outputs [16]

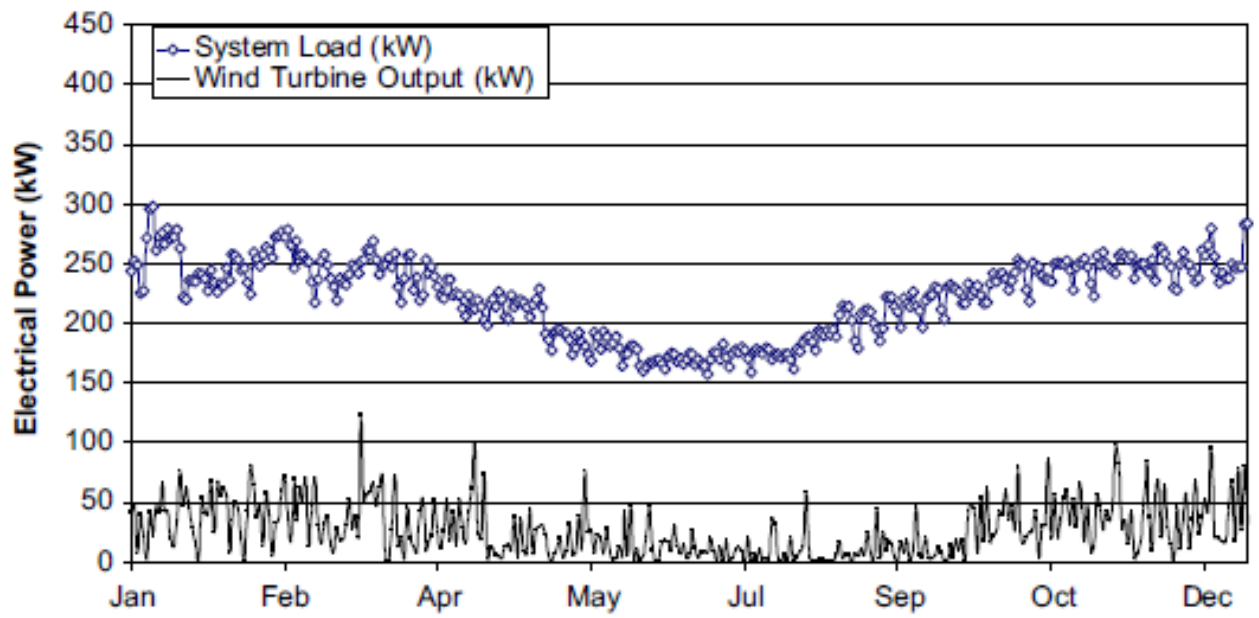

Figure 6. Example of a low-penetration wind-diesel system outputs [16] 


\begin{tabular}{|c|c|c|c|}
\hline \multirow{2}{*}{$\begin{array}{l}\text { Penetration } \\
\text { class }\end{array}$} & \multirow[b]{2}{*}{ Operating characteristics } & \multicolumn{2}{|c|}{ Penetration } \\
\hline & & $\begin{array}{c}\text { Peak } \\
\text { instantaneous }\end{array}$ & $\begin{array}{l}\text { Annual } \\
\text { average }\end{array}$ \\
\hline Low & $\begin{array}{c}\text { Diesel runs full-time. Wind power reduces net } \\
\text { load on diesel. All wind energy goes to primary } \\
\text { load. No supervisory control system }\end{array}$ & $<50 \%$ & $<20 \%$ \\
\hline Medium & $\begin{array}{l}\text { Diesel runs full-time. At high wind power levels, } \\
\text { secondary loads dispatched to ensure sufficient } \\
\text { diesel loading or wind generation is curtailed. } \\
\text { Requires relatively simple control system. }\end{array}$ & $50 \%-100 \%$ & $20 \%-50 \%$ \\
\hline High & $\begin{array}{l}\text { Diesel may be shut down during high wind } \\
\text { availability. Auxiliary components required to } \\
\text { regulate voltage and frequency. } \\
\text { Requires sophisticated control system. }\end{array}$ & $100 \%-400 \%$ & $\begin{array}{l}50 \%- \\
150 \%\end{array}$ \\
\hline
\end{tabular}

Table 1. Wind-diesel classification [15]

\subsection{Technical challenges of wind-diesel hybrid system}

Hybrid wind-diesel systems with high penetration of wind power have three plant modes: diesel only (DO), wind-diesel (WD) and wind only (WO). In DO mode, the maximum power from the wind turbine generator (WTG) is always significantly less than the system load. It is the mode of classical diesel power plant. In this case, the diesel generators (DG) never stop operation and supply the active and reactive power demanded by the consumer load. Frequency regulation is performed by load sharing and speed governors controlling each diesel engine and voltage regulation is performed by the synchronous voltage regulators in each generator. The main goals of maximize fuel savings or minimize generation costs to supply the actual load [17] is achieved by careful planning/scheduling of the DG having into account factors such as their specific fuel consumption, their rated power, etc.

Wind-Diesel mode can be considered as a diesel plant with the wind turbine as a negative load. It is the mode of many low/medium wind penetration power wind-diesel systems already implemented in Nordic communities in Yukon [18], Nunavut [19] and in Alaska [20]. In this case, the WTG power is frequently approximately the same as the consumer load and in addition to DG(s), WTG(s) also supply active power. Some new problems appear in this mode like to determine the diesel spinning reserve (the wind power can disappear in any moment due to the unpredictable wind resource and the current load can overload the diesel(s) currently supplying), or to assure a minimum diesel load needed by some engines (this situation can happen at high wind power levels and low loads). Under these conditions, two operating modes are possible: (1) the diesel can be allowed to run continuously, or (2) the diesel can be stopped and started, depending on the instantaneous power from the wind and the requirements of the load. Running the diesel continuously decreases the load factor, with an increase in the aforementioned diesel operating costs. 
Using the energy storage unit showed in figure 4 can solve both problems. The second problem can be solved by the use of the dump load showed in figure 4 or reducing the power coming from the wind turbine. Some variable speed wind turbines have this possibility [21]. Also in this mode additional reactive power must be generated, because wind turbines are normally reactive power consumers, although adding capacitor banks or overexciting the synchronous generators can solve this. However, the first obstacle with this perspective results from the operation constraints of diesels. Beyond a certain penetration, the obligation to maintain idle the diesel at any time, generally around $25-30 \%$ of its nominal output power, forces the system to function at a very inefficient regime. Also, this limits the wind energy to a level of too weak penetration and the wind turbines act only as a negative charge for the network. Indeed, for low and medium penetration systems, the diesel consumes, even without load, approximately $50 \%$ of the fuel at nominal power output. These systems are easier to implement but their economic and environmental benefits are marginal [22].

The use of high penetration systems allows the stop of the thermal groups, ideally as soon as the wind power equals the instantaneous charge, to maximize the fuel savings. This is the wind only mode. The WO mode is only possible if the power coming from the wind turbine(s) is greater than the consumed power by the load (with a safety margin). Because no diesel generators run in this mode, auxiliary components are required to regulate voltage and frequency. The frequency is controlled through the active power balance. To accomplish this active power balance, the energy storage system can be added to store the surplus active power from the wind turbine or retrieve power in the periods when the wind power is less than current load; also the surplus wind power can be consumed by dump loads. The voltage is controlled by the reactive power balance and it is normally achieved through synchronous condensers which deliver the reactive power needed by the loads and the wind turbine. To supply power uninterruptedly, the size of the energy storage has to be big enough to assure power to the load during transitions from the wind power source to the diesel power source when there is a failure or absence of wind energy. In the meantime, the high-penetration wind diesel systems without storage (WDHPWS) is subject to complex technical problems [23], [24] which did that a single project of this type, without any storage, is presently operational in Alaska [20].

During time intervals when the excess of wind energy over the charge is considerable the diesel engine must still be maintained on standby so that it can quickly respond to a wind speed reduction (reduce the time of starting up and consequent heating of the engine). This is an important source of over consumption because the engine could turn during hours without supplying any useful energy. Assuming optimum exploitation conditions [25], the use of energy storage with wind-diesel systems can lead to better economic and environmental results, allows reduction of the overall cost of energy supply and increase the wind energy penetration rate (i.e., the proportion of wind energy as the total energy consumption on an annual basis) [16]. 


\section{Choice of the energy storage device for a high penetration wind-diesel hybrid system}

Presently, the excess wind energy is stored either as thermal potential (hot water), an inefficient way to store electricity as it cannot be transformed back in electricity when needed or in batteries which are expensive, difficult to recycle, a source of pollution (leadacid) and limited in power and lifecycle. The fuel cells propose a viable alternative but due to their technical complexity, their prohibitive price and their weak efficiency, their appreciation in the market is still in an early phase. The required storage system should be easily adaptable to the hybrid system, available in real time and offer smooth power fluctuations.

Due to technical, economical and energetic advantages demonstrated by the compressed air energy storage (CAES) in hybrid systems at large scale (figure 7) use in the USA and Germany, we investigated the possibility to associate the wind-diesel with compressed air energy storage system for medium and small scale applications (isolated sites).

The choice of this system was not only based on the successes of large scale CAES system. The energy storage in the form of compressed air is suitable for both wind and diesel applications. Moreover, the CAES presents an interesting solution for the problem of strong stochastic fluctuations in wind power by offering a high efficiency conversion rate $(60-70 \%$ for a complete charge-discharge cycle). It, also, uses conventional materials that are easy to recycle and can support an almost unlimited number of cycles [26].

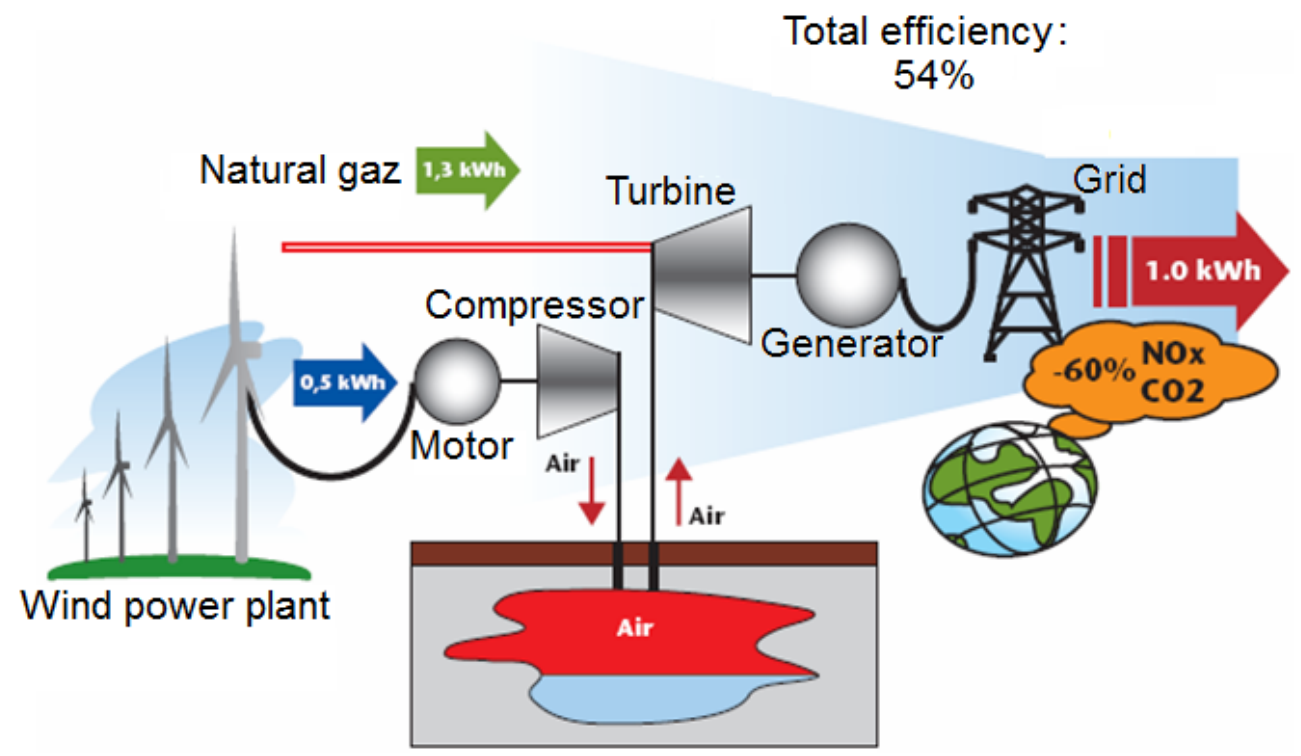

Figure 7. Illustration of the large-scale wind-compressed air hybrid system 


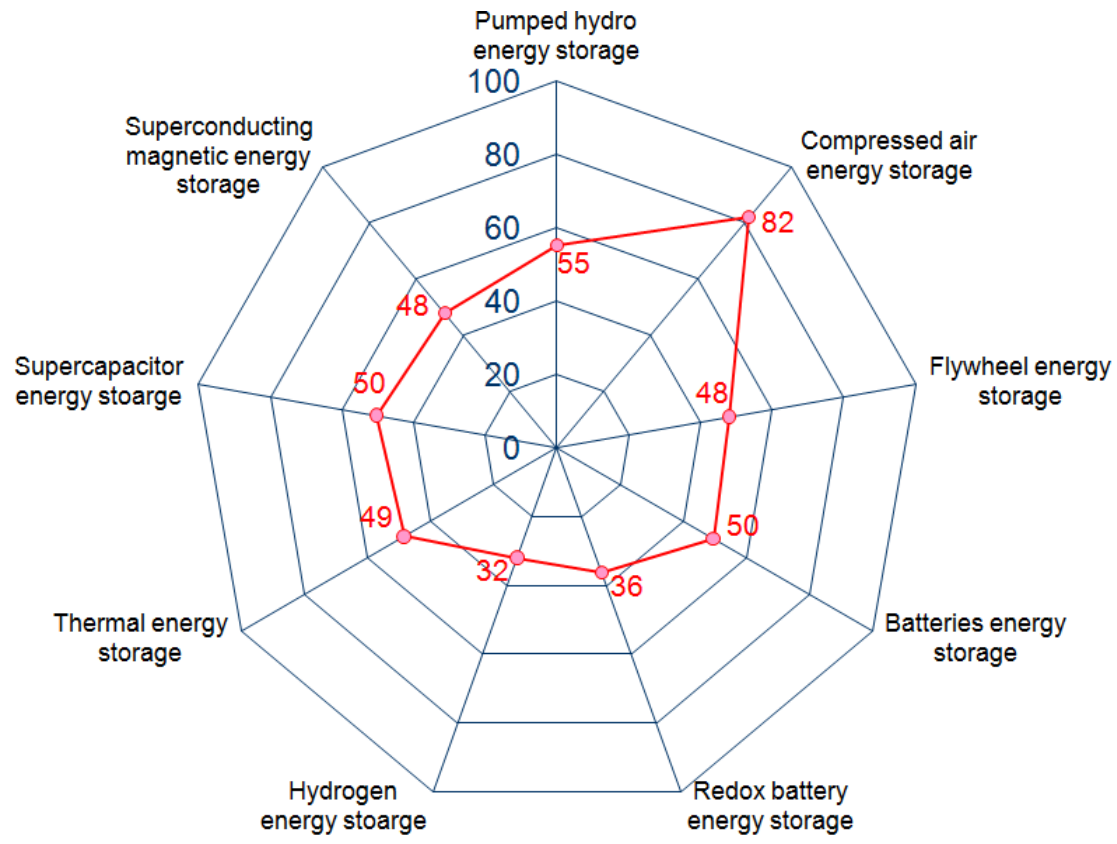

Figure 8. Performance index of different energy storage systems

A detailed study based on a critical analysis of all techno-economical characteristics of the possible energy storage technologies (for example, cost, efficiency, simplicity, life time, maturity, self-discharging, reliability, environmental impact, operation constraints, energy and power capacity, adaptability with wind-diesel system, contribution to reduce of fuel consumption, etc.); it was proposed a solution that meets all the technical and financial requirements while ensuring a reliable electricity supply of these sites. It is the wind-diesel hybrid system with compressed air energy storage (WDCAHS). This study demonstrates the value of compressed air storage for a high penetration wind-diesel hybrid system and its advantages with regard to the other energy storage technologies. It was based on the aggregation in a "performance index» of technical, economic and environmental characteristics of various storage methods [27]. The results of this analysis and the values of the performance index are illustrated in the figure 8 for different possible strategies of storage.

The performance index is the measure of the applicability of a technique of storage to a specified application [27]. For another application than the power supply of a remote area, the values of the performance index can be different. The determination of the indication of performance is done using a decision matrix that helps to balance the importance of each characteristic (15 criteria, for example, cost, self-discharging, reliability, time response, efficiency, simplicity, life time, maturity, environmental impact, operation constraints, energy and power capacity, adaptability with wind-diesel system, operational constraints, contribution to reduce of fuel consumption, etc.) of the storage system with regard to the specific requirements of the envisaged application. 
It is easy to establish from the figure 8 that the compressed air energy storage system (CAES) answers the choice criteria with a performance index of approximately $82 \%$.

\section{Medium-scale wind-diesel-compressed air hybrid system}

\subsection{Operation principle}

The medium scale wind-diesel-compressed air hybrid system (MSWDCAHS) (figure 9) can be used, for example, in the case of remote villages or islands with important level of local electrical load (few hundred kilowatts to few tens of MW). MSWDCAHS combined with diesel engine supercharging, will increase the wind energy penetration rate. Supercharging is a process consisting of a preliminary compression that aims to increase the density of the engine's air intake, in order to increase the specific power (power by swept volume). During periods of strong wind (when wind power penetration rate - WPPR, defined as the quotient between the wind generated power and the charge is greater than 1 ; WPPR $>1$ ), the wind power surplus is used to compress the air via a compressor and store it in a tank. The compressed air is then used to supercharge the diesel engine with the two-fold advantage of increasing its power and decreasing its fuel consumption. The diesel generator works during periods of low wind speed, i.e., when the wind power is not sufficient to sustain the load.

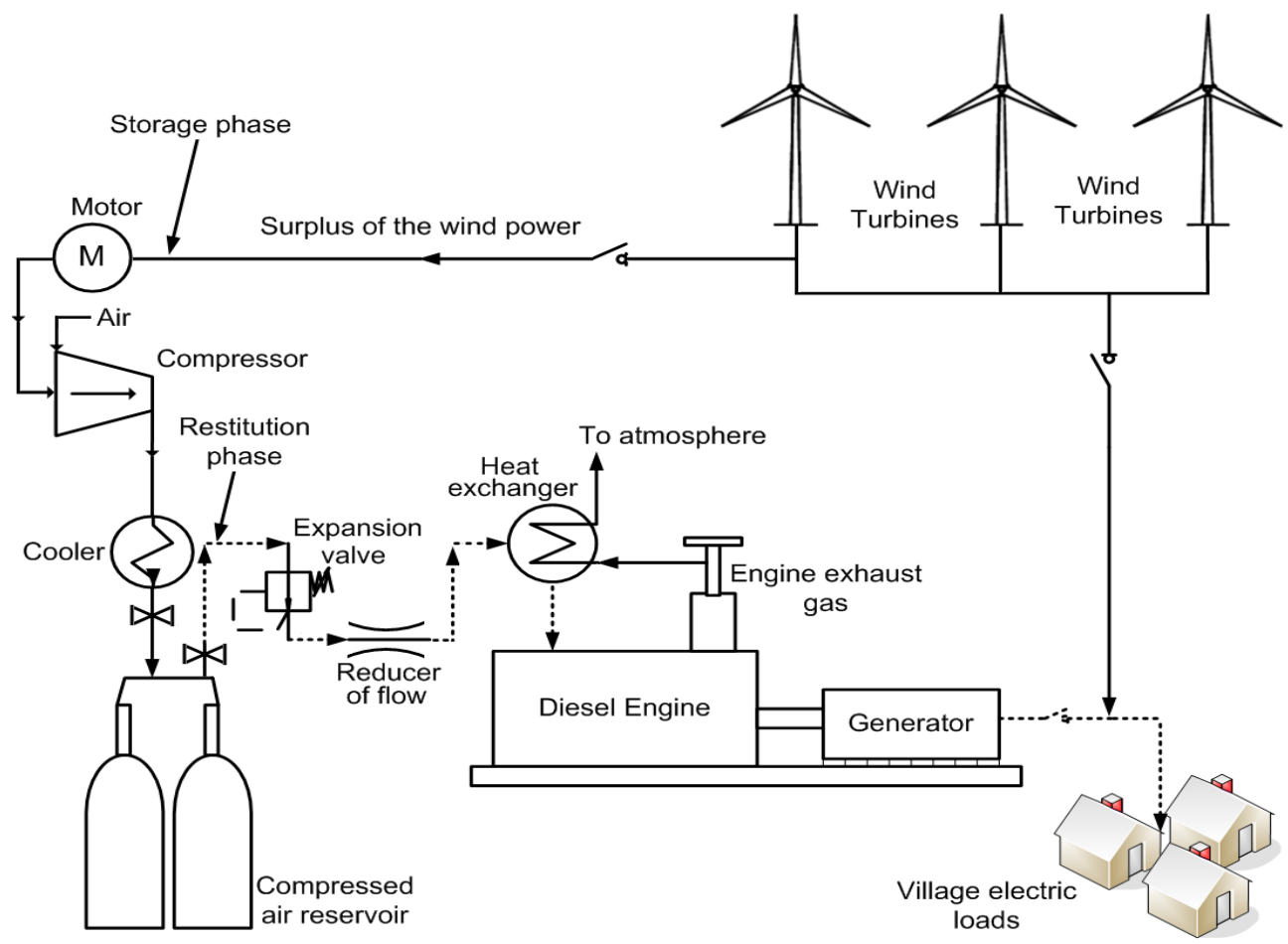

Figure 9. Illustration of the medium-scale wind-diesel compressed air hybrid system 


\subsection{Technical advantages of an additional supercharging of diesel generator with stored compressed air}

Most diesel generators used in remote areas (medium-scale case) are already equipped with a turbocharging system via a turbocharger. However, this type of system loses its advantages during operation at low regime because its efficiency is directly related to the quantity of exhaust gases. To understand the advantage of an additional turbocharging of diesel engine and the operation limits of a turbocharger, we present in figure 10 an example which compares a diesel engine in two functioning modes: atmospheric (without turbocharger) and turbocharged.

Figure 10 shows that as compared to an atmospheric diesel engine with an engine capacity of $10 \mathrm{~L}$, supercharging can increase the values of the indicated efficiency of the engine (maximal efficiency $=45 \%$ ) and extend the operating range in the area of high efficiency thanks to the large permissible quantity of air into the engine. For a load of 600 N.m, the efficiency of the supercharged engine is about $38 \%$ compared with that of atmospheric engine (14\%), i.e., an increase about $170 \%$. On the other hand, increasing the applied load on the engine triggers a degradation of the diesel performance due to the operation limits of the turbocharger and to the increase of the heat loss through the cylinder walls. However, this does not exclude the fact that the efficiency for high loads are better through supercharging as compared to the efficiency obtained with atmospheric engine (an increase about $64 \%$ for a load of 1200 N.m).

The figure 10 also shows that the compression ratio reaches its maximal value (figure 10) only for the highest loads (this corresponds to high flow and pressure of exhaust gas). This delay to reach the maximal pressure of the compressed air at the engine intake will delay the achievement of the maximal power of the turbocharged engine. The objective of the additional supercharging via the stored compressed air is, then, to maximize the overall efficiency of the diesel engine (figure 10), by several improvements:

- Improving the combustion efficiency by operating the engine at all times with an optimal air/fuel ratio, which does not allow the turbocharger to operate alone.

- $\quad$ Reducing the pumping losses for the low pressure loop of the thermodynamic cycle of diesel engine to increase the work supplied for the same quantity of burned fuel.

- Increasing the specific power (power per swept volume unit) of the diesel engine and its performance.

- Increase the intake pressure at a level which allows a decrease of the fuel quantity injected while maintaining the same maximal pressure in the cylinder of the engine. This allows decreasing the mechanical and thermal constraints due to the supercharging.

\section{Small-scale wind-diesel-compressed air hybrid system}

The small scale wind-diesel-compressed air hybrid system (SSWDCAHS) (figure 11) can be used, for example, in the case of remote telecom infrastructures that the level of electrical 
load is not very high (few tens of $\mathrm{kW}$ ). These infrastructures require continuous, stable, and safe energy supply to maximize the deployment, signal strength, and coverage of the cellular phone. The difference between MSWDCAHS and the SSWDCAHS is the utilization method of the stored compressed air. Indeed, when the output energy of a wind turbine is more than energy demand at the load side ( $\mathrm{WPPR}>1$ ), the excess energy will be converted into the mechanical form using high pressure compressors. The energy is stored in a high pressure reservoir as potential energy. In a case that the wind turbine cannot deliver the required energy at the load side $(\mathrm{WPPR}<1)$, the stored mechanical energy will be converted to the electrical energy. In this case, the stored compressed air will be expanded into a pneumatic generator that supply the load. In this step, the diesel generator is stopped. The genset works during periods of low wind speed and only if the compressed air energy storage capacity is not sufficient to supply the pneumatic generator.

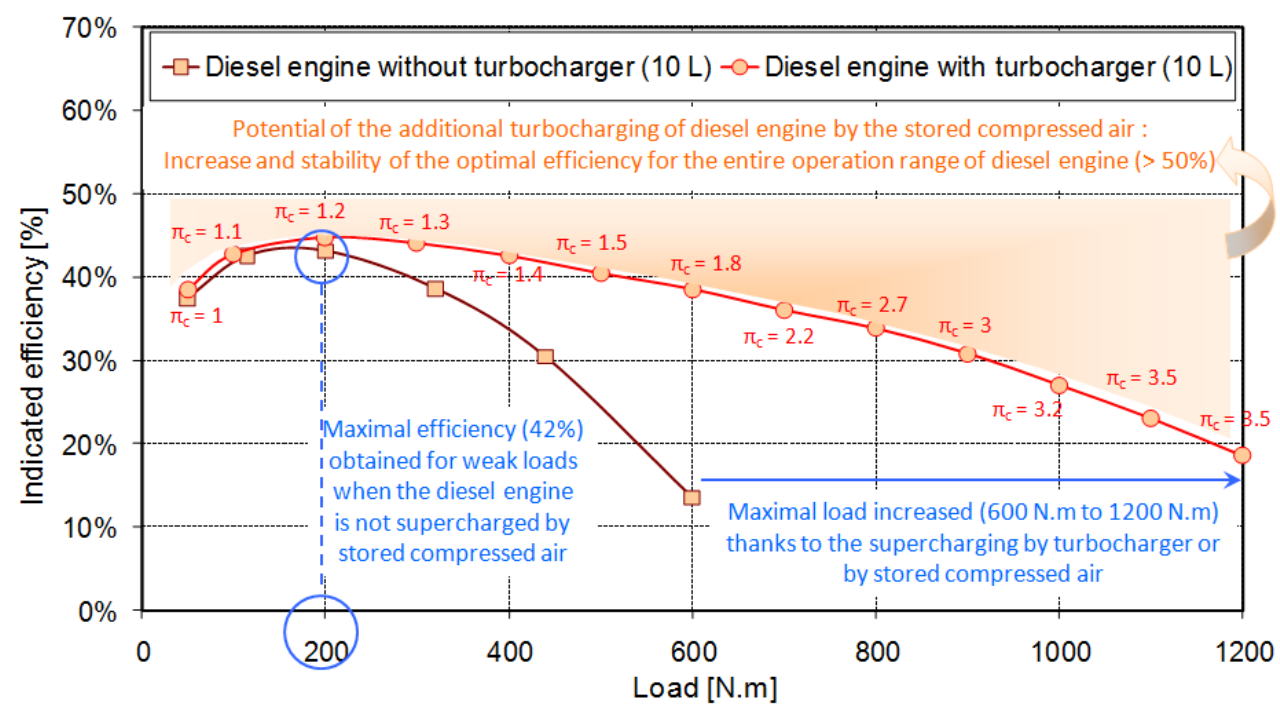

Figure 10. Potential of the additional supercharging of diesel engine by the stored compressed air 


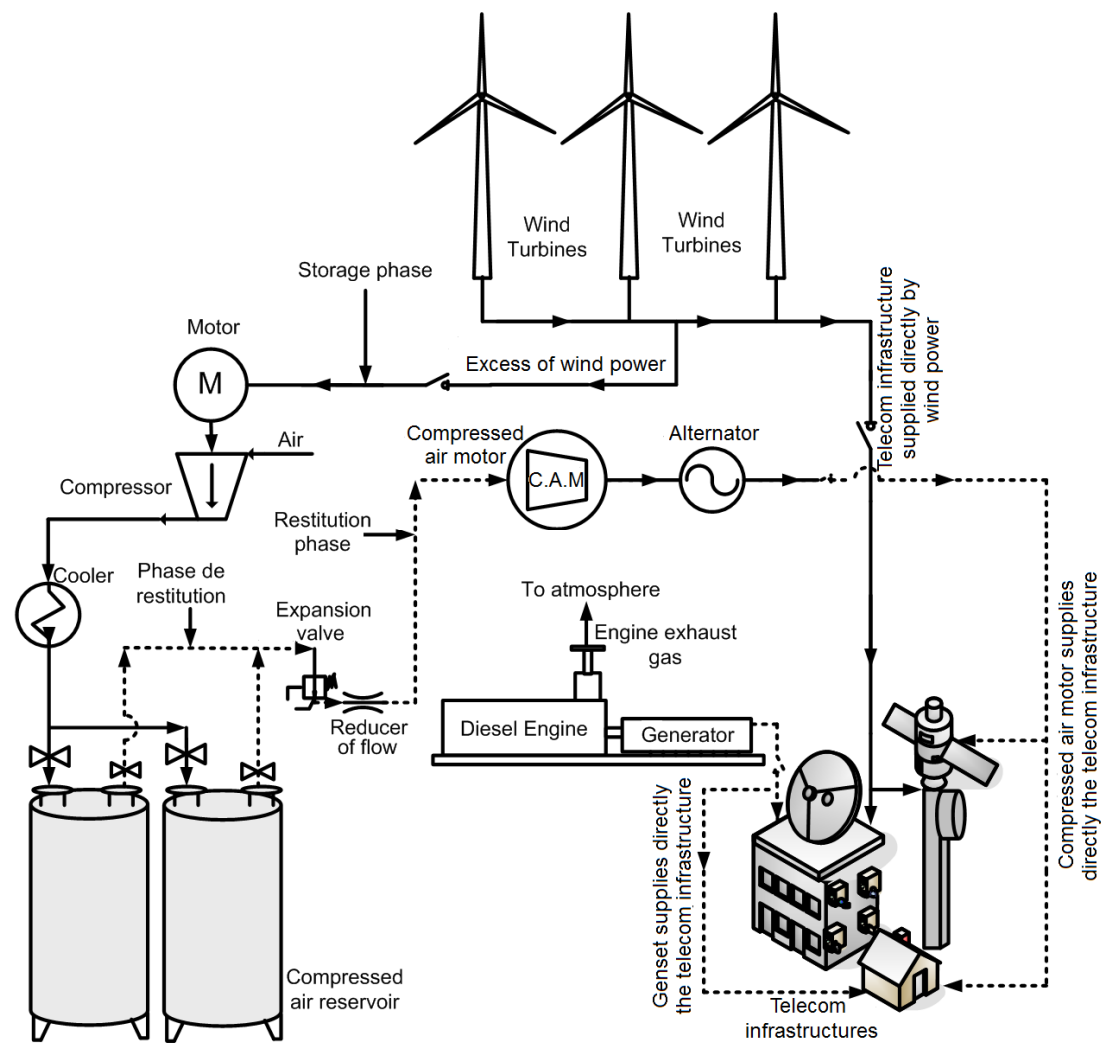

Figure 11. Illustration of the small-scale wind-diesel compressed air hybrid system

\section{Advantages of wind-diesel-compressed air hybrid system}

WDCAHS represents an innovative concept and it has a very important commercial potential for remote areas as it is based on the use of diesel generators already in place. To our knowledge, the type of WDCAHS that is, proposed in this paper was never the object of a commercial application or an experimental project, and we did not find studies relative to the design or performance of such a system in the scientific literature.

The lack of information on the economics, as well as on performances and reliability data of such systems is currently the main barrier to the acceptance of wind energy deployment in the remote areas. WDCAHS is designed to overcome most of the technical, economic and social barriers that face the deployment of wind energy in isolated sites [28]. Indeed, implementation costs are minimized and reliability is increased by using the existing diesel generators. Our WDCAS solution is threefold: modification and adaptation of the existing engines at the intake level (for medium-scale), addition of a generator that functions with compressed air (for small-scale), addition of a wind power plant and addition of an air compression and storage system. 
Using information available [29-31], and performance analysis [32-33], we estimate that on a site with appreciable wind potential, the return on investment (ROI) for such installation is between 2 and 5 years, subject to the costs of fuel transport. For sites accessible only by helicopters the ROI can be less than a year [25].

This analysis does not take into account the raising prices of fuel, nor GHG credit which only tend to reduce the ROI [34].

\section{Case study applied to the medium scale wind-diesel-compressed air system}

To estimate the potential gain of the MSWDCAS on a target site, we recovered the hourly wind speed data and the hourly electrical load of the diesel engine on the site of the village of Tuktoyaktuk in the Northwest Territories of Canada on the Arctic coast. The maximum and average electric loads of this village are respectively $851 \mathrm{~kW}$ and $506 \mathrm{~kW}$. Initially, the village's electricity is supplied by 2 diesel generators, each having $544 \mathrm{~kW}$ as maximal power. To these generators a wind plant composed of 4 wind turbines of type Enercon, each having a nominal power equal to 335 kilowatts, a total power equal to $1340 \mathrm{~kW}$ was added. We estimated fuel consumption, greenhouse gases (GHG) emissions and maintenance cost of diesel engines for different scenarios: diesel only, wind-diesel hybrid system (WDHS) without CAES and wind-diesel hybrid system with CAES, over a period of 1 year (2007 year's). Figures 12-18 illustrate the results.

Figures 12 and 13 represent the profile of the average wind speed corrected to hub height of wind turbines, the profile of the monthly electric load of the village, the variations of power supplied by wind turbines, the variations of power supplied by diesel generators before and after hybridization with the wind turbines, the operation frequency of diesel engines after hybridization and the profiles of the power directed toward the storage system and that absorbed by the compressor. These figures show that the maximal average consumption of the village occurs during the fall and winter seasons due to the increase of the electric load for the heating. Unfortunately, the highest wind speed is registered during the spring and summer seasons where the average electricity consumption decreases approximately 200 $\mathrm{kW}$ in comparison with that of the winter.

Figure 14 shows the operation frequency of diesel engines after the hybridization with the wind turbines. The number of functioning hours of diesel engines depends strongly of the availability of the wind power and the level of the electric load of the village. During 2007, the

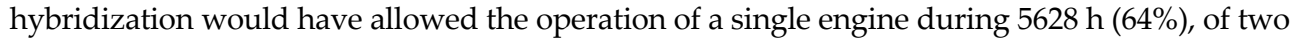
engines during $1766 \mathrm{~h}(20 \%)$ and stop both diesel generators approximately $1366 \mathrm{~h}(16 \%)$.

Figure 15 represents the operation frequency of diesel engines according to their supercharging mode (with or without CAES). This figure shows that the hybridization allows the functioning of diesel engines supercharged by stored compressed air during 3608 $\mathrm{h}(41 \%)$. During $3786 \mathrm{~h}(43 \%)$, the diesel engines are operating without CAES and they are stopped for $1366 \mathrm{~h}$. 


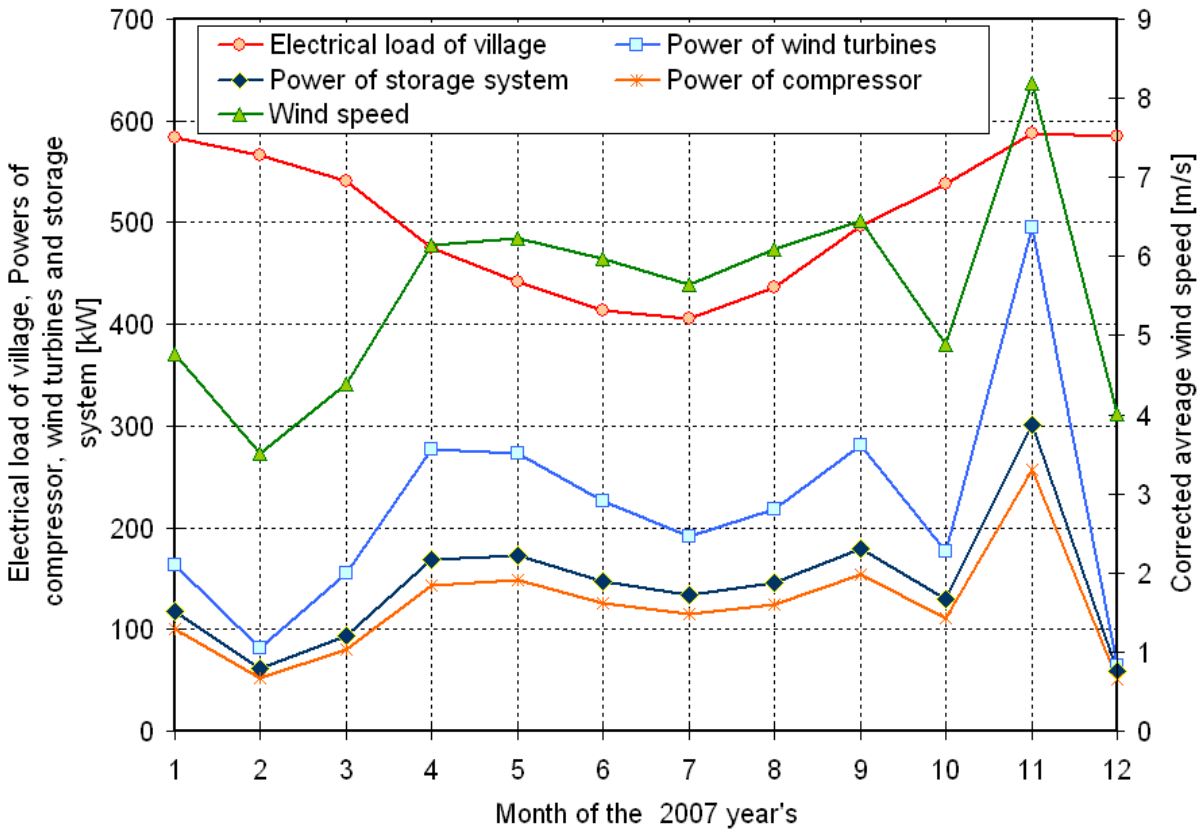

Figure 12. Average wind speed and power profiles of the: electrical load, wind turbines, compressor and energy storage system

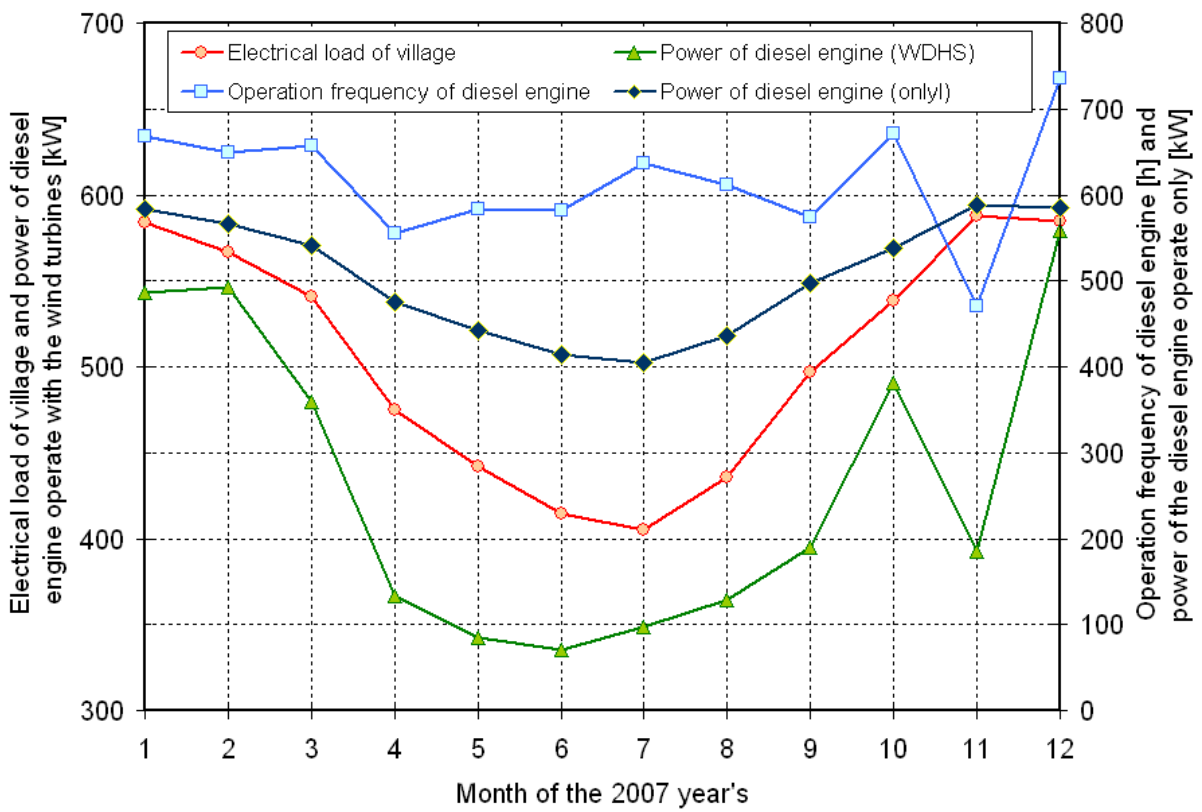

Figure 13. Operation frequency and power curve of diesel engines and profile of the electrical load 


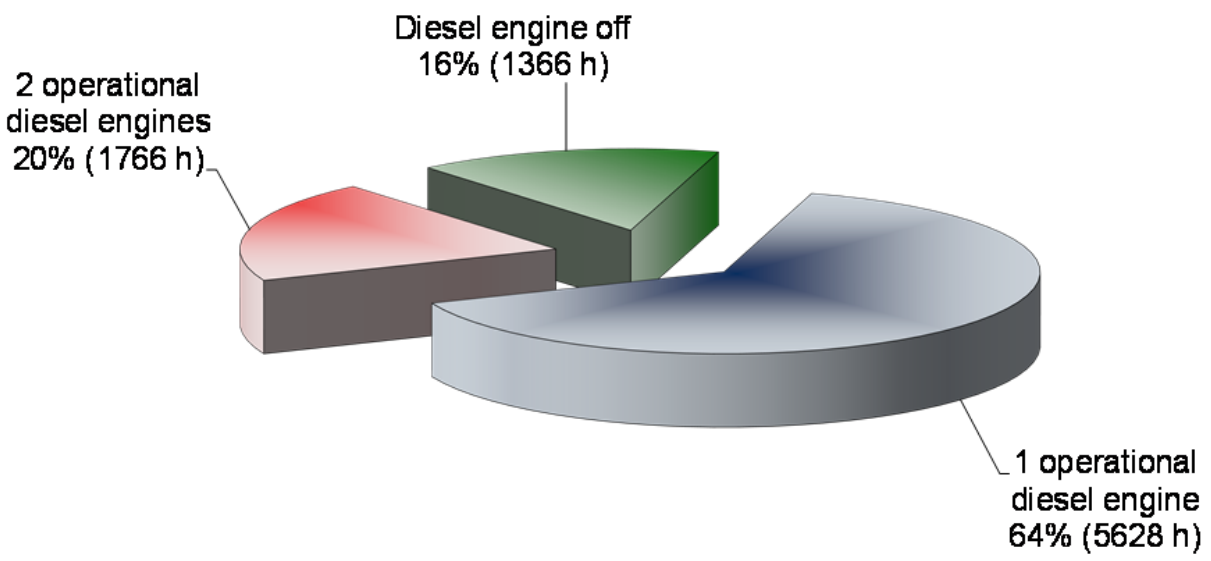

Figure 14. Operation frequency of diesel engines after the hybridization with the wind turbines

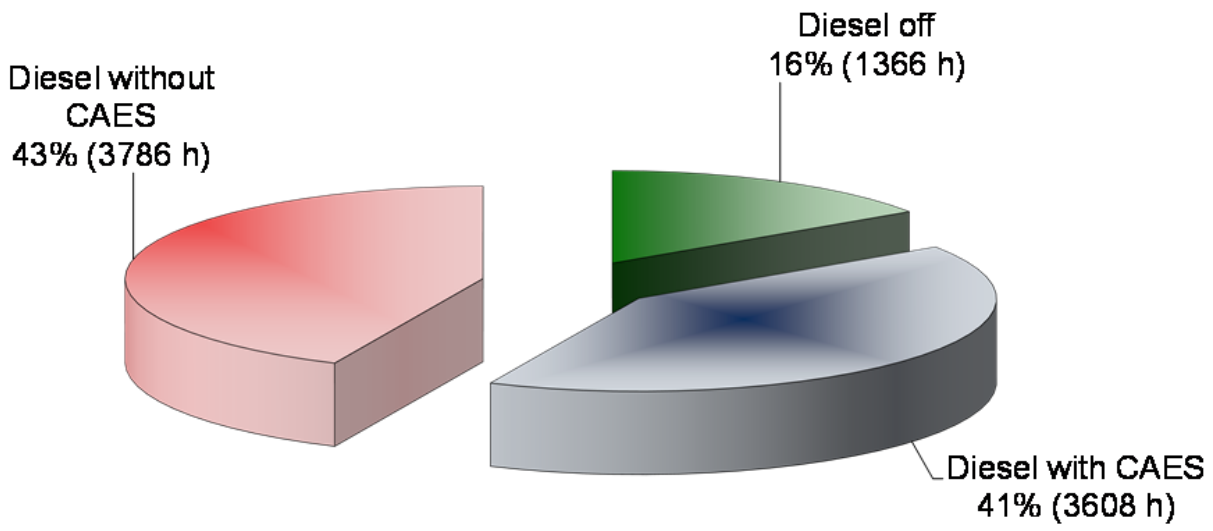

Figure 15. Operation frequency of diesel engines according to their supercharging mode

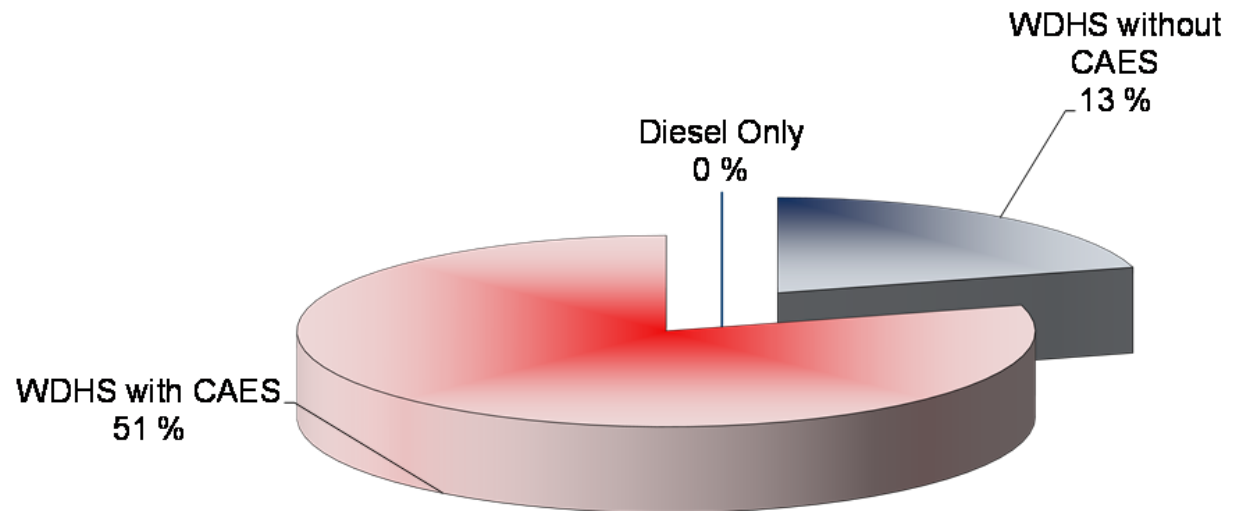

Figure 16. Annual reduction of maintenance and operation costs 
The estimation of the annual reduction of maintenance and operation costs, based on the reduction of operation time of the two diesel engines, is represented in figure 16. The base line for comparison is the scenario without hybridization, where no savings in the cost of maintenance can be realized. The WDHS without CAES allows 13\% reduction while with CAES, this rate increases to $51 \%$. It is important to mention that the supercharged diesel engine by compressed air stored allows operating with a single diesel engine, whatever the load of the village. On the other hand, a permutation between the two supercharged engines will be necessary to avoid the blocking of some mechanical moving pieces of the engine.

Figure 17 shows the monthly consumption of fuel along a year (2007). Compared with the base line scenario, the use of WDHS without CAES allows fuel reduction varying from 3,000 litres (minimal value) in February to 36,000 litres (maximal value) in November. On the other hand, a WDHS with CAES will significantly increase this economy with a minimum fuel saving of 10,000 litres (February) and a maximum of 53,000 litres (November).

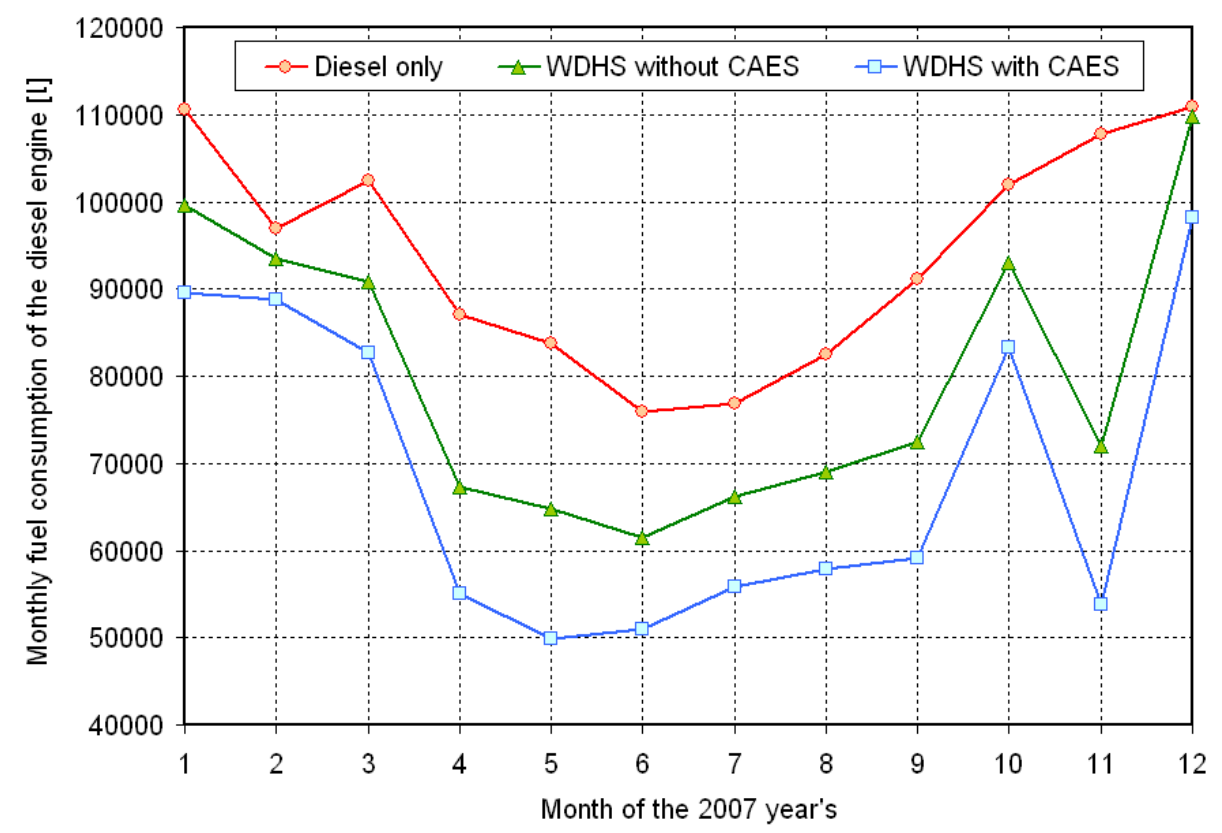

Figure 17. Monthly consumption of fuel along a 2007 year's

Figure 18 illustrates the annual fuel savings. The hybridization between wind energy and diesel engines without CAES reduces by 168,324 L the annual fuel consumption (15\%) while with CAES, this reduction increases to $27 \%(303,143 \mathrm{~L})$. This quantity $(27 \%)$ is equivalent to 848.8 tons of $\mathrm{CO} 2$ or the annual emission of 167 automobiles and light trucks traveling $15,000 \mathrm{~km}$ per year. In Table 2, we review the quantity of greenhouse gases (GHG) avoided thanks to the use of MSWDCAHS. 


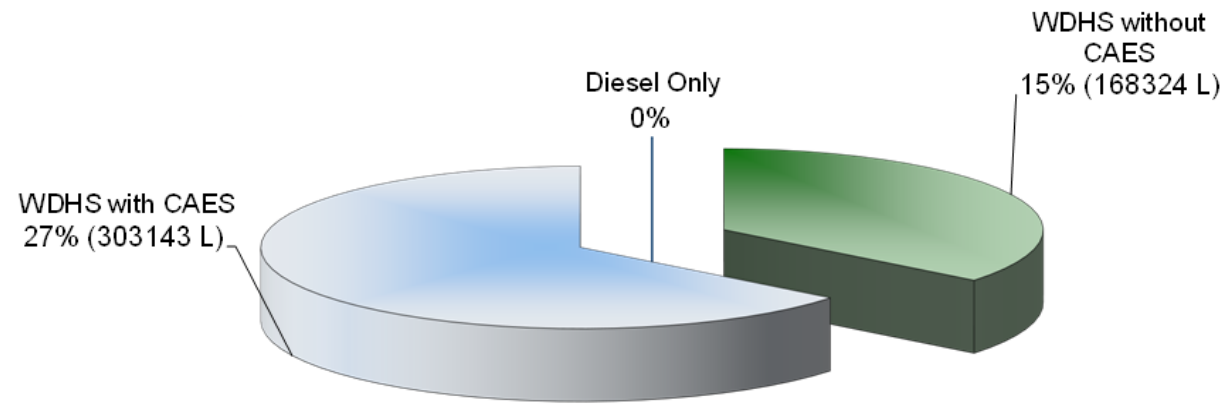

Figure 18. Annual fuel savings

\begin{tabular}{|l|l|l|}
\hline Name of the substance & Emission Factor $\left(\mathrm{kg} / \mathrm{m}^{3}\right)$ & $\begin{array}{l}\text { Total value of emissions } \\
\text { (tones) }\end{array}$ \\
\hline Carbon dioxide $\left(\mathrm{CO}_{2}\right)$ & 2800 & 848.8 \\
\hline Carbon monoxide $(\mathrm{CO})$ & 13.954 & 4.23 \\
\hline Sulfur dioxide $\left(\mathrm{SO}_{2}\right)$ & 0.083 & 0.025 \\
\hline Oxides of nitrogen (NOx) & 52.532 & 15.925 \\
\hline Volatile organic Compounds $(\mathrm{VOC})$ & 1.344 & 0.408 \\
\hline Total suspended Particles $(\mathrm{TSP})$ & 1.018 & 0.309 \\
\hline Particles with diameters $\leq 10 \mu \mathrm{m}\left(\mathrm{P}_{10}\right)$ & 0.814 & 0.247 \\
\hline Particles with diameters $\leq 2.5 \mu \mathrm{m}\left(\mathrm{P}_{2.5}\right)$ & 0.786 & 0.238 \\
\hline
\end{tabular}

Table 2. Quantities of GHG avoided by MSWDCAHS

\section{Case study applied to the small scale wind-diesel-compressed air system}

To estimate the potential gain of the SSWDCAS on a target site, we recovered the hourly wind speed data (for one month, April 2005) on the site of the telecom station of BellCanada situated in Kuujjuarapik (North of Quebec) at 1130 kilometers from Montreal (figure 19). The wind speed data of this site for the month April 2005 are shown in figures 20 . 
The electrical load of the station is considered constant, about $5 \mathrm{~kW}$, including the secondary load of heating. The diesel generator guarantees the supply's continuity of the station by providing exactly the power level consumed by the load. The case study was conducted using two types of wind turbines: the first is a Bergey [35] (10kW, already installed on site) and the second is a PGE (currently named Endurance, 35kW) [36] that we propose to be able to increase the penetration of wind energy and use the excess of this energy to produce the compressed air. Figures 21-24 illustrate the obtained results.

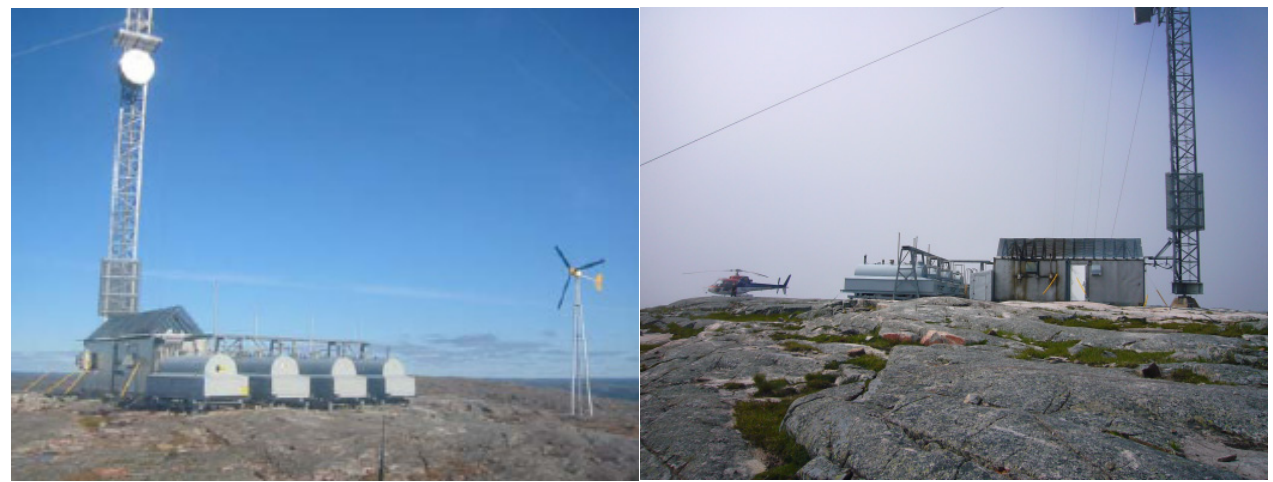

Figure 19. Telecom station of Bell-Canada at Kuujjuarapik [37]

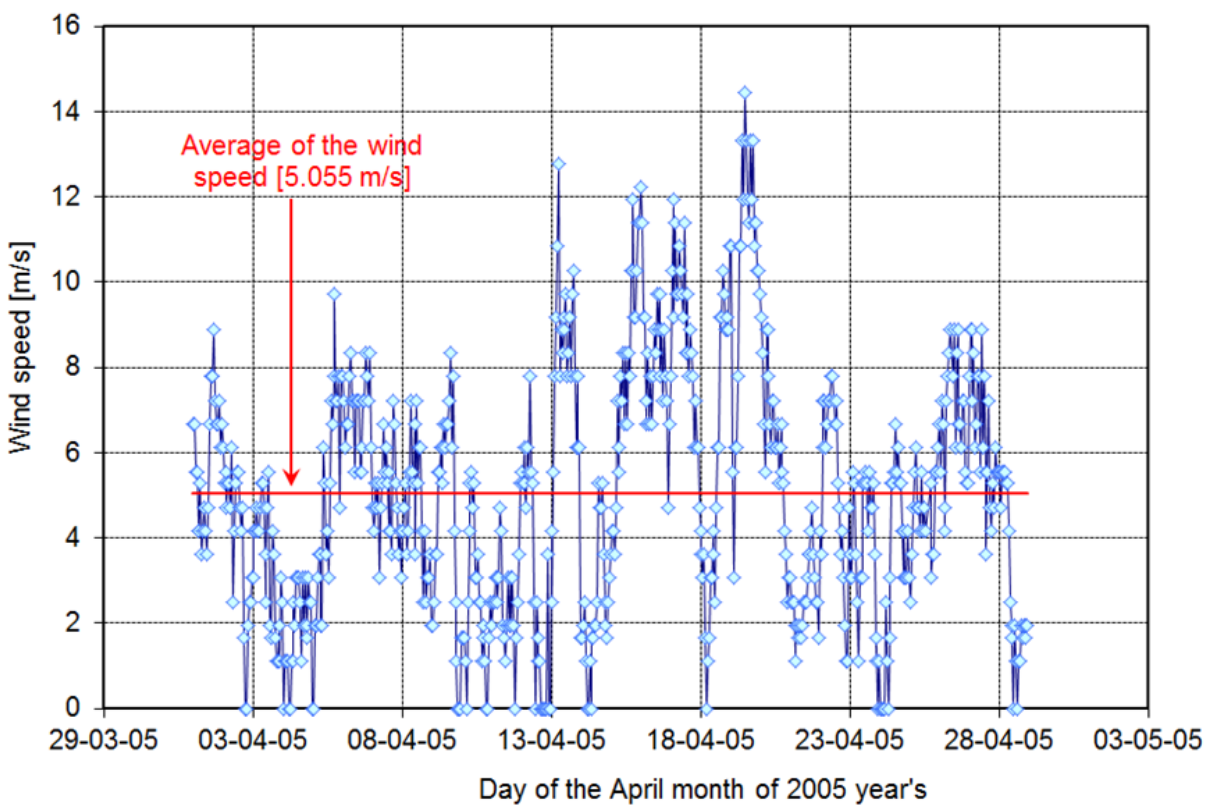

Figure 20. Wind speed data of the Kuujjuarapik site along an April month of 2005 year's 


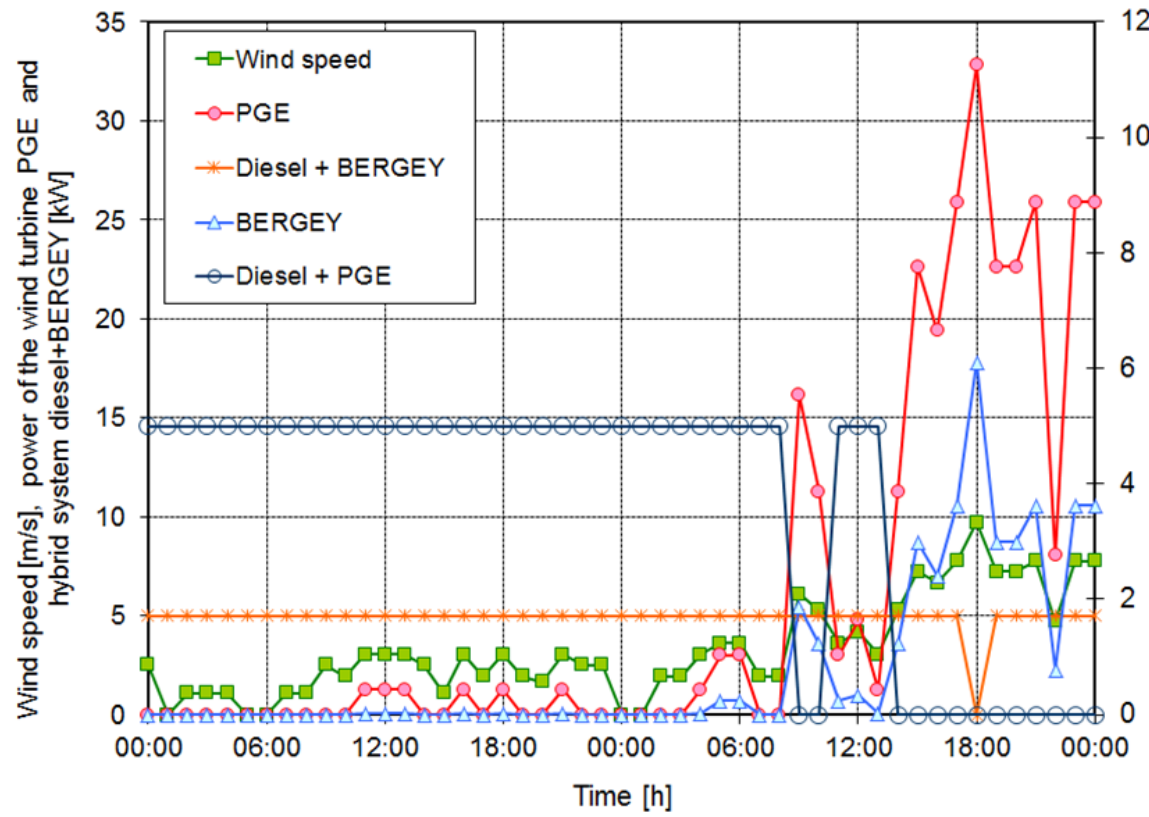

Figure 21. Operating modes of the studied systems along period from 4 to 5 April 2005

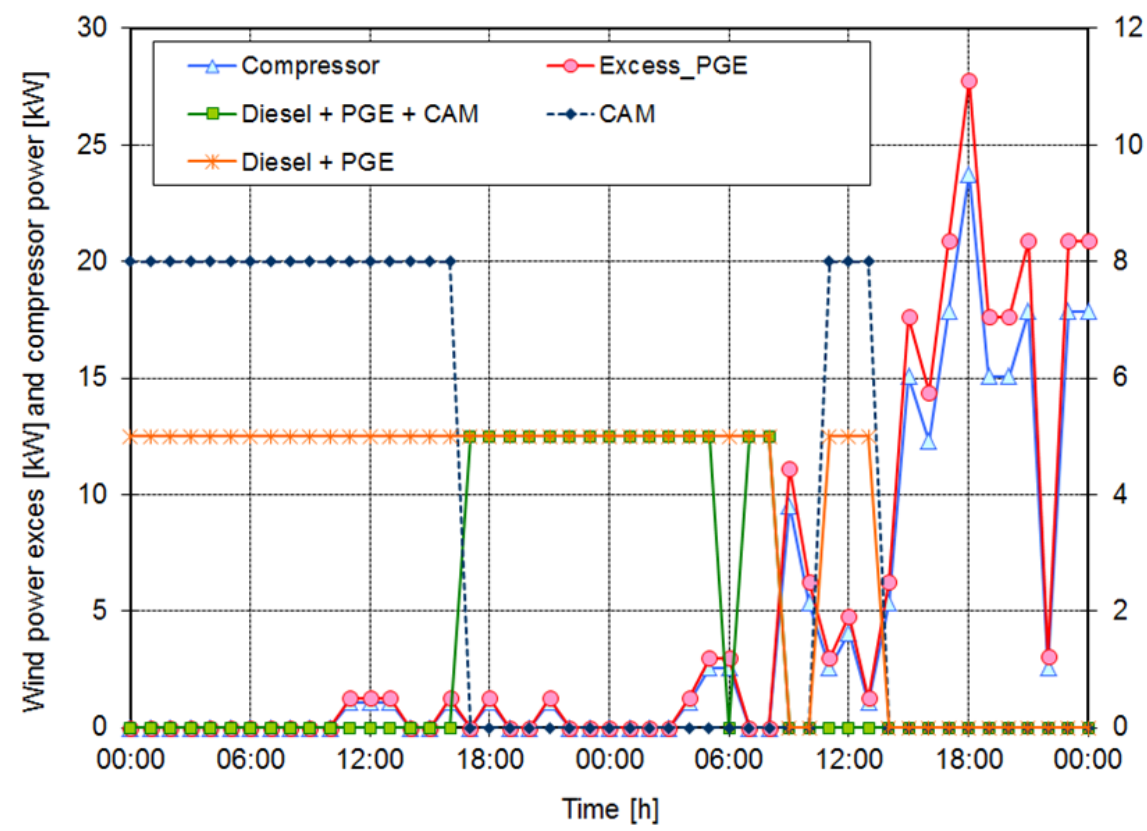

늠

Figure 22. Operating modes of the studied systems along period from 4 to 5 April 2005 
In figures 21 and 22, the legends (Diesel + Bergey), (Diesel + PGE) and (diesel + PGE + CAM) represent the power supplied by diesel generator according to the different types of hybridizations with two models of wind turbines and a compressed air energy storage system, respectively.

It is interesting to observe, in figures 21 et 22, the advantages of hybridization (Diesel + PGE + CAM) that appears in the short duration of the diesel operation time (DOT). Indeed, it can stop completely the diesel generator for 33 hours during two days of operation (saving of $69 \%$ of the DOT) compared to 13 hours of shutdown of the diesel (27\% of DOT is avoided) obtained through the system (Diesel + PGE) and 1 hour (saving of $2 \%$ of the DOT) during which the diesel will be stopped thanks to the hybridization between it and Bergey wind turbine..

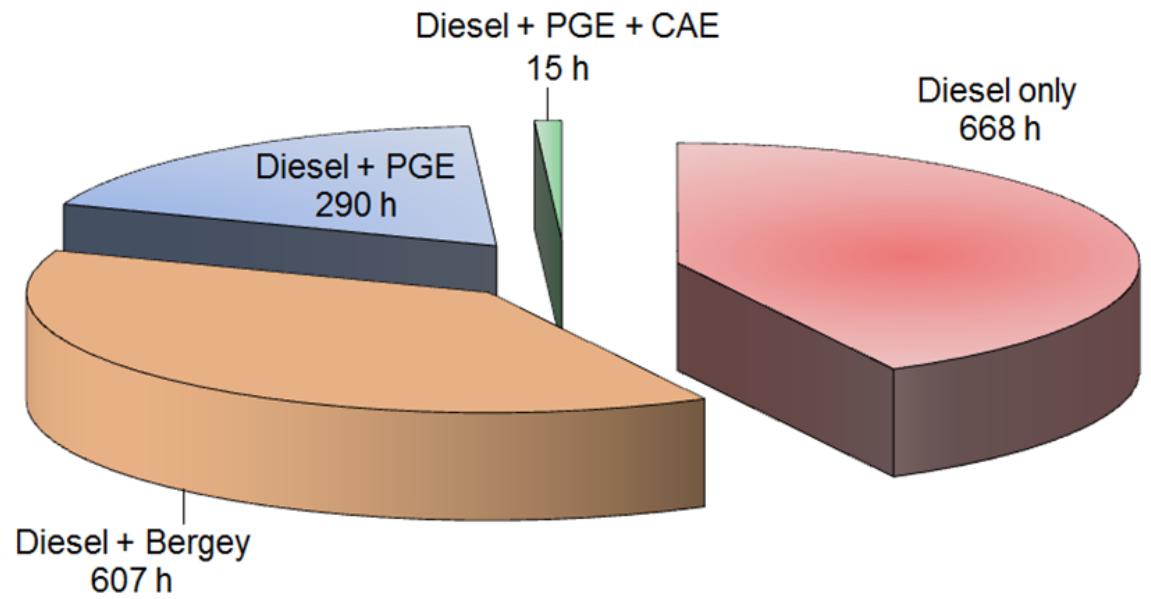

Figure 23. Operating time of diesel generator according to the exploitation scenarios

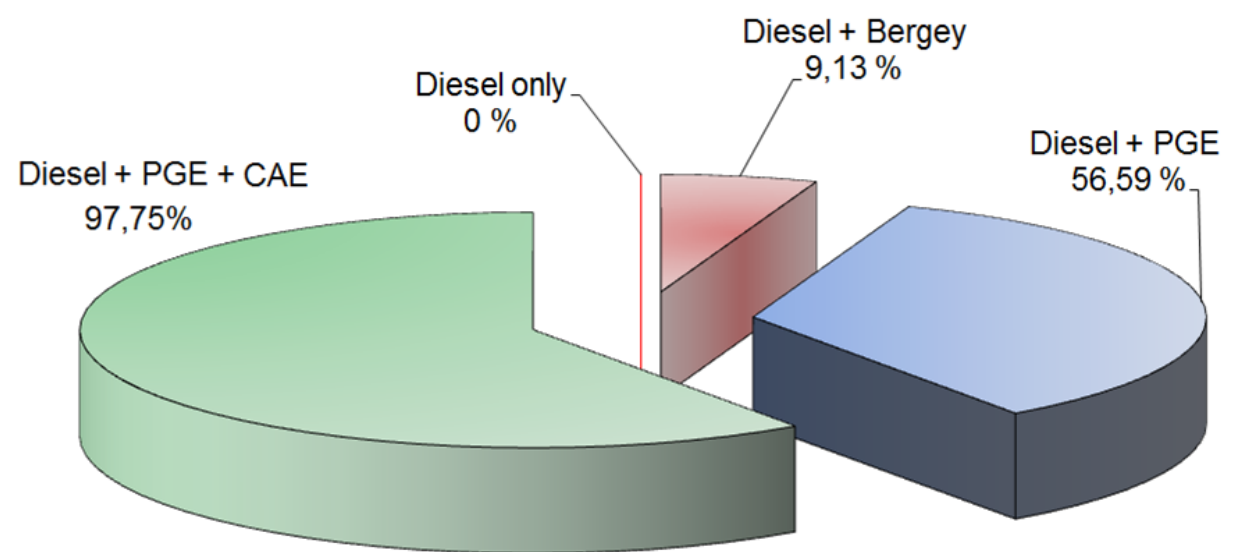

Figure 24. Fuel saving according to the exploitation scenarios 
Figure 23 represents the operating time of diesel generator according to the functioning scenario of the system (diesel only, Bergey + diesel, PGE + diesel or PGE + diesel + CAM). Figure 23 shows that hybridization between the Bergey wind turbine and diesel does not allow a remarkable decrease in the operation frequency of the diesel generator (DG) that runs about $91 \%$ of operating time in April 2005 (607 h). But by combining the DG to a PGE wind turbine, the DG will work almost $43 \%(290 \mathrm{~h})$ of time during the month of April and 15 $\mathrm{h}(2 \%)$ if it works in hybridization with the CAM and a PGE wind turbine.

Figure 24 represents the fuel saving according to the functioning scenario of the system (diesel only, Bergey + diesel, PGE + diesel or PGE + diesel + CAM), Figure 24 shows that WDHS avoids approximately 139 liters of fuel (9\% saving in fuel consumption) if the diesel is associated with a Bergey wind turbine. However, this rate increases to 57\% (863 liters), if the hybridization of the diesel generator is done with the PGE wind turbine. On the other hand, the hybridization between diesel generator, compressed air generator and PGE wind turbine increases this fuel saving very significantly where the amount of fuel avoided is approximately 1491 liters (98\%). The fuel saved thanks to SSWDCAHS (during the month of April 2005), allows to reduce the greenhouse gases (GHG) emission approximately 4 tons, which is equivalent to the GHG amount emitted by one automobile or light truck traveling 15,000 km per year. In Table 3, we review the quantity of greenhouse gases (GHG) avoided thanks to the use of WDCAHS.

\begin{tabular}{|c|c|c|}
\hline Name of the substance & Emission Factor $\left(\mathrm{kg} / \mathrm{m}^{3}\right)$ & $\begin{array}{c}\text { Total value of emissions } \\
\text { (tones) }\end{array}$ \\
\hline Carbon dioxide $\left(\mathrm{CO}_{2}\right)$ & 2800 & 4.174 \\
\hline Carbon monoxide $(\mathrm{CO})$ & 13.954 & 0.023 \\
\hline Sulfur dioxide $\left(\mathrm{SO}_{2}\right)$ & 0.083 & 0.007 \\
\hline Oxides of nitrogen $(\mathrm{NOx})$ & 52.532 & 0.108 \\
\hline Volatile organic Compounds $(\mathrm{VOC})$ & 1.344 & 0.009 \\
\hline Total suspended Particles $(\mathrm{TSP})$ & 1.018 & 0.008 \\
\hline Particles with diameters $\leq 10 \mu \mathrm{m}\left(\mathrm{P}_{10}\right)$ & 0.814 & 0.008 \\
\hline Particles with diameters $\leq 2.5 \mu \mathrm{m}\left(\mathrm{P}_{2.5}\right)$ & 0.786 & 0.008 \\
\hline
\end{tabular}

Table 3. Quantities of GHG avoided by SSWDCAHS during one month (April 2005) 


\section{Conclusion}

WDCAHS (medium and small scales) represents an innovative concept designed to overcome most of the technical, economic and social barriers that face the deployment of wind energy in isolated sites. Indeed, implementation costs are minimized and reliability is increased by using the existing diesel generators. Thus, the results, theoretical and experimental, obtained have demonstrated the great potential of wind-diesel-compressed air energy storage system for two types of applications: small and medium scale. The application of these systems on real case studies has demonstrated that the fuel economy and the saved GHG obtained with MSWDCAHS (for medium-scale) and SSWDCAHS (small-scale) is about $30 \%$ and $98 \%$ respectively.

Despite the low average wind speed that characterize the sites chosen for the case studies, remarkable savings may be obtained through the use of compressed air, by avoiding the consumption of large fuel quantities and by allowing the use of a single diesel engine (instead of two: medium-scale case) or by stopping the diesel thanks to the compressed air motor (small-scale case). This allows not only reducing the exploitation deficit of diesel engines supplying the autonomous networks in remote areas, but also to prolong engine life-cycle and reduce maintenance costs. These percentages, especially for medium-scale application, can be increased if the wind-diesel-compressed air hybrid system is used in the sites characterized by a good wind energy potential (average wind speed about $8-9 \mathrm{~m} / \mathrm{s}$ ).

However, in future works, the calculation of the energy cost $(\mathrm{kW} / \mathrm{h})$, based on the investment cost and the purchase of new equipment (wind turbines, CAES equipment, etc.) will allow determining the system's economic viability for remote applications.

Finally, further investigation and analysis, as well as building and testing a prototype, are required to validate the present conclusions. This can be validated on the future bed-test of TechnoCentre éolien at Rivière-au-Renard (Quebec, Canada).

\section{Author details}

Hussein Ibrahim

TechnoCentre Éolien, Gaspé, QC, Canada

Adrian Ilinca

Université du Québec à Rimouski, Rimouski, QC, Canada

\section{References}

[1] G. Iwanski, W. Koczara, "Isolated Wind-Diesel Hybrid Variable Speed Power Generation System", presented at EVER 2009, Monaco 2009, May 26-29. 
[2] Ken Ash, Trevor Gaunt, Sissy-qianqian Zhang, Erkki Lakervi, Innovative solutions and best practices for electrification of remote areas, CIGRE SC-C6 (COLL 2007), Working Group C6-13 "Rural Electrification", Topic B.

[3] Chemmangot Nayar, High Renewable Energy Penetration - Diesel Generator Systems, Electrical India Vol. 50, N6, June 2010.

[4] L. Grzesiak, W. Koczara, M. da Ponte, "Power Quality of the Hygen Autonomous Load - Adaptive Adjustable Speed Generating System", Proc. of Applied Power Electronics Conf. APEC'99. Dallas, USA, March 1999, pp. 398 - 400.

[5] Kim Ah-You, Greg Leng, Énergies renouvelables dans les communautés éloignées du Canada, Programme des énergies renouvelables pour les communautés éloignées, Ressources Naturelles Canada.

[6] Weis TM, Ilinca A. The utility of energy storage to improve the economics of winddiesel power plants in Canada. Renewable Energy 2008;33(7):1544e57.

[7] La stratégie énergétique du Québec 2006e2015. L'énergie pour construire le Québec de demain. http://www.mrnf.gouv.qc.ca/energie/eolien.

[8] I. Baring-Gould, M. Dabo, "Technology, Performance, and Market Report of WindDiesel Applications for Remote and Island Communities", Proc. of WINDPOWER 2009, Chicago, Illinois May 4-7, 2009.

[9] Chedid, R. B., S. H. Karaki et C. EI-Chamali. ,"Adaptive fuzzy control for wind-diesel weak power systems", Energy Conversion, IEEE Trans on, vol. 15, nO I, p. 71-78.

[10] Saha, T. K., et D. Kastha. ,"Design Optimization and Dynamic Performance Analysis of a Stand-Alone Hybrid Wind-Diesel Electrical Power Generation System ", Energy Conversion, IEEE Trans on, vol. 25, no 4, p. 1209-1217.

[11] Abbey, C.," A Stochastic Optimization Approach to Rating of Energy Storage Systems in Wind-Diesel Isolated Grids ", Power Systems, IEEE Trans. on, vol. 24, no I, p. 418426.

[12] Wind/Diesel Systems Architecture Guidebook, AWEA, 1991.

[13] http://en.wikipedia.org/wiki/Wind-Diesel_Hybrid_Power_Systems

[14] W. Koczara, Z. Chlodnicki, E. Ernest, N. Brown, "Hybrid Adjustable Speed Generation System", proceedings on 3rd International Conference on Ecological Vehicles \& Renewable Energies, Monaco 2008, March 27-30.

[15] J.G. McGowan, J.F. Manwella and S.R. Connors, "Wind/diesel energy systems: Review of design options and recent developments", Solar Energy, Volume 41, Issue 6, Pages 561-575, 1988.

[16] Timothy M. Weis, Adrian Ilinca, The utility of energy storage to improve the economics of wind-diesel power plants in Canada, Renewable Energy, Volume 33, Issue 7, July 2008, Pages 1544-1557.

[17] J. Kaldellis et al, “Autonomous energy systems for remote islands based on renewable energy sources", in Proceedings of EWEC 99, Nice 1999. 
[18] J.F. Maisson «Wind Power Development in Sub-Arctic Conditions with Severe Rime Icing ", Presented at the Circumpolar Climate Change Summit and Exposition, Whitehorse, Yukon, 2001

[19] www.nunavutpower.com

[20] B. Reeves " Kotzebue Electric Association Wind Projects », Proceedings of NREL/AWEA 2002 Wind-Diesel Workshop, Anchorage, Alaska, USA, 2002

[21] P. Ebert P and J. Zimmermann, "Successful high wind penetration into a medium sized diesel grid without energy storage using variable speed wind turbine technology", in Proceedings of EWEC 99, Nice 1999.

[22] Singh V. Blending Wind and Solar into the Diesel Generator Market. Renewable Energy Policy Projet (REPP) Research Report, Winter 2001, No. 12, Washington, DC.

[23] Y. Jean, P. Viarouge, D. Champagne, R. Reid, B. Saulnier, «Perfectionnement des outils pour l'implantation des éoliennes à Hydro-Québec», rapport IREQ-92-065, 1992

[24] R. Gagnon, A. Nouaili, Y. Jean, P. Viarouge; «Mise à jour des outils de modélisation et de simulation du Jumelage Éolien-Diesel à Haute Pénétration Sans Stockage et rédaction du devis de fabrication de la charge de lissage», Rapport IREQ-97-124-C, 1997.

[25] Ilinca A, Chaumel JL. Implantation d'une centrale éolienne comme source d'énergie d'appoint pour des stations de télécommunications. Colloque international sur l'énergie éolienne et les sites isolés, Îles de la Madeleine, 2005.

[26] H. Ibrahim, R. Younès, A. Ilinca, J. Perron, Investigation des générateurs hybrides d'électricité de type éolien-air comprimé. Numéro spécial CER'2007 de la Revue des énergies renouvelables, Parrainée par l'UNESCO, Éditée par le CDER, Algérie, Août 2008 .

[27] H. Ibrahim, A. Ilinca, J. Perron, Investigations des différentes alternatives renouvelables et hybrides pour l'électrification des sites isolés, rapport interne, UQAR, LREE-03, 2008.

[28] T.M. Weis, A. Ilinca, J.Paul. Pinard, Stakeholders' perspectives on barriers to remote wind-diesel power plants in Canada Energy Policy, Volume 36, Issue 5, May 2008, Pages 1611-1621

[29] Hunter R, Elliot G. Windediesel systems e a guide to the technology and its implementation. Cambridge (UK): Cambridge University Press; 1994.

[30] HOMER v2.0 e the optimisation model for distributed power. NREL. www.nrel.org.

[31] Robb D. Making a CAES for wind energy storage. North American Wind Power, June 2005.

[32] Ibrahim H, Younès R, Ilinca A. Optimal conception of a hybrid generator of electricity. CANCAM02007 ETS-39, Toronto, Canada. p. 358 - 359.

[33] Ibrahim H, Ilinca A, Perron J. Moteur diesel suralimenté, bases et calculs, cycles réel, théorique et thermodynamique. Rapport interne, UQAR-UQAC, LREE-02; Novembre 2006. 
[34] Ibrahim H, Ilinca A, Younès R, Perron J, Basbous T. Study of a hybrid wind-diesel system with compressed air energy storage. IEEE Canada, electrical power conference 2007, "Renewable and alternative energy resources", EPC2007, Montreal, Canada, October 25e26, 2007.

[35] http://www.bergey.com/

[36] http://www.endurancewindpower.com/

[37] Bell-Canada, www.bell.ca 